O. M. Pihnastyi, orcid.org/0000-0002-5424-9843, S. M. Cherniavska, orcid.org/0000-0002-9438-6965
National Technical University "Kharkiv Polytechnic Institute”, Kharkiv, Ukraine, e-mail: pihnastyi@gmail.com

\title{
ANALYSIS OF STRESS IN THE CONVEYOR BELT (MAXWELL-ELEMENT MODEL)
}

Purpose. For a conveyor belt, the material of which corresponds to the Maxwell-element model, to analyze the causes of the occurrence of longitudinal dynamic stresses and investigate the peculiarities of the propagation of dynamic stresses along the route of material transportation.

Methodology. To calculate the value of static and dynamic stresses arising in the conveyor belt, the apparatus of mathematical physics was used.

Findings. A wave equation is written that determines the propagation of longitudinal vibrations in a conveyor belt, the material of which corresponds to the Maxwell-element model. An expression is obtained for calculating the speed of propagation of elastic vibrations along the conveyor belt, the frequency of vibrations and their wavelength. The characteristic relaxation time of disturbances is determined. The method of successive approximation was used to solve the wave equation. The estimation of the characteristic time of acceleration of the conveyor belt, at which there is no destruction of the material of the conveyor belt, is given.

Originality. PDE-models of conveyor-type transport systems are improved, which are used to design belt speed control systems under restrictions on speed control modes. It is shown that under the modes of acceleration or deceleration of the conveyor belt, the effects associated with the occurrence and propagation of dynamic stresses along the conveyor belt, due to the characteristics of the material corresponding to the Maxwell-element model, are insignificant.

Practical value. The results obtained make it possible to determine the limitations on the modes of acceleration or deceleration of the conveyor belt, preventing its damage and increased wear. This opens up prospects for designing effective control systems for the parameters of a conveyor belt, unevenly loaded with material along the transport route.

Keywords: conveyor, distributed system, belt speed control, conveyor, PDE model, Maxwell element, Hookean element

Introduction. Conveyor-type transport systems are widely used in the mining industry [1]. This is primarily due to the fact that: a) conveyer is one of the most economic ways of the material transportation from the extraction place to the place of shipment; b) the conveyor allows moving the material through difficult rugged terrain [2]. Transport costs are up to $20 \%$ of the cost of the extracted material at a material load factor in the transport system of $0.5-0.7$ [3]. With an increase in the length of the transport system and a decrease in the load factor, the growth of unit transport costs is nonlinear, which can lead to an increase in costs by several times. To reduce energy costs, systems for controlling the belt speed $[4,5]$, the value of the input material flow $[6,7]$, combined methods and methods based on the energy management methodology [8] are used. The belt speed regulation allows reducing the specific energy losses for material transportation up to $30 \%$ [9]. Dividing the transport system into separate sections [10] and using multi-motor systems allow material to move through the transport system at different belt speeds for different sections [11], which saves energy. This is of particular importance for long multi-section transport systems [2]. The speed or input flow regulation leads to a change in the productivity of the section, and therefore to a change in the power required to operate the conveyor section in standard mode. The presence of the power switching modes leads to the appearance of dynamic stresses in the belt, which can be the reason of its damage. In this regard, in the design of control systems that determine the power switching modes, the issue of taking into account the limitations associated with the occurrence of dynamic stresses, which can exceed the limiting value and lead to the destruction of the belt, is relevant.

Formulation of the problem. Changing the power mode of the conveyor section leads to a change in the tractive moment, and, accordingly, to the subsequent acceleration (braking) of the conveyor belt. For an asynchronous motor with a phase rotor, the dependence of the traction torque of the electric motor $M_{\text {eng }}$ on the rotational speed $n_{\text {eng }}$ at the nominal values of the torque $M_{\text {eng } 0}$ and rotational speed $n_{\text {eng } 0}$ of the electric motor is shown in

(c) Pihnastyi O. M., Cherniavska S. M., 2021
Fig. 1. The process of acceleration (braking) of the conveyor belt with the material occurs in several stages, each of which is characterized by an abrupt change in the tractive moment of the electric motor. Such a sawtooth change in the tractive moment depending on the change in the engine speed (Fig. 1) is the source of the existence of dynamic stresses in the belt. The presence of dynamic stresses imposes additional restrictions on the modes of acceleration (braking) of the conveyor belt.

These restrictions must be taken into account when synthesizing algorithms for optimal control of the flow parameters of the transport system.

The linear density of the material $[\chi]_{0}(t, S)$ along the transport route at the time $t$ at the point of the conveyor section with the coordinate $S \in\left[0, S_{d}\right]$ can be calculated from the relation [11]

$$
\theta_{0}(\tau, \xi)=(H(\xi)-H(\xi-G)) \frac{\gamma_{1}\left(\tau-\Delta \tau_{\xi}\right)}{g\left(\tau-\Delta \tau_{\xi}\right)}+H(\xi-G) \psi(\xi-G),
$$

where

$$
\begin{gathered}
G=\int_{0}^{\tau} g(\alpha) d \alpha ; \quad \tau=t / T_{d} ; \quad \xi=S / S_{d} ; \quad H\left(S_{d} \xi\right)=H(S) \\
\psi(\xi)=\Psi(S) /[\chi]_{0 \max } ; \quad \gamma_{1}(\tau)=\lambda_{1}(t) T_{d} / S_{d} /[\chi]_{0 \max } \\
g(t)=\mu_{\psi}(t) T_{d} / S_{d} ; \quad \theta_{0}(\tau, \xi)=[\chi]_{0}(t, S) /[\chi]_{0 \max }
\end{gathered}
$$

The expression $\theta_{0}(\tau, \xi)$ determines the relationship between the linear density of the material $[\chi]_{0}(t, S)$, the speed of the belt $\mu_{\psi}(t)$ and the input flow of the material $\lambda_{1}(t)$ at the initial distribution of the material with the density $\Psi(S)$. The average time $T_{d}$ of material passage along the transport route by the length of the conveyor section $S_{d}$ is taken as the characteristic time of the process. The value $[\chi]_{0 \text { max }}$ corresponds to the maximum permissible linear density of the material for the conveyor section. The choice of characteristic values $T_{d}, S_{d}$, $[\chi]_{0 \text { max }}$ is conditional.

The analysis of the propagation of dynamic stresses in the conveyor belt is performed for the Maxwell model of an elastic element (Fig. 2) with the elastic modulus of the element $E$ and viscosity $\eta$ 


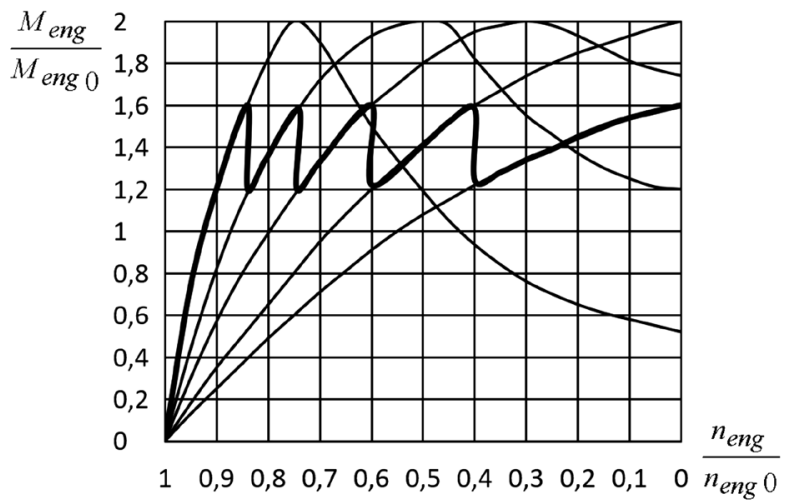

Fig. 1. Mechanical characteristic of a phase rotor induction motor

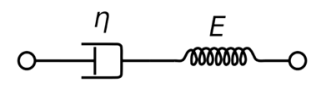

Fig. 2. Maxwell element

$$
\frac{1}{E} \frac{d \sigma(t, S)}{d t}+\frac{\sigma(t, S)}{\eta}=\frac{d \varepsilon(t, S)}{d t} .
$$

The Maxwell elastic element model can be used for conveyor belts containing rubber, nylon and polyester [17]. When the traction load changes as a result of power switching, the Hooke element is deformed by an amount $\sigma_{0} / E$, and the viscous element is deformed at a constant speed $\sigma_{0} / \eta$. The total strain $\varepsilon(t, S)$ is determined by integrating (1)

$$
\frac{\sigma_{0}}{E}+\frac{\sigma_{0}}{\eta} t=\varepsilon(t, S) ; \quad \varepsilon(0, S)=\sigma_{0} / E .
$$

With a long time of the presence of stress, the deformation $\varepsilon(t, S)$ becomes quite significant. For a constant strain speed $v_{\varepsilon} \approx$ const the solution to (1) has the form

$$
\sigma(t, S)=\eta v_{\varepsilon}\left(1-e^{-t / t_{0}}\right) ; \quad \frac{d \varepsilon(t, S)}{d t}=v_{\varepsilon}, \quad t_{0}=\eta / E .
$$

With a long time of the deformation process, the stress in the conveyor belt tends to a constant value.

The solutions to (1) demonstrate the characteristic behavior of the belt material (Maxwell element) when loaded. To study the propagation of dynamic stresses in a conveyor belt, let us construct an equation that takes into account the boundary conditions represented by the relationship between the traction moments and the speed of the conveyor belt.

Literature review. The properties of the material from which the conveyor belt is made determine the process of dynamic stress propagation. In the article [12], a comparative analysis of the Voigt-element and Maxwell element models is given and, using the Lagrange equations, the calculation of the dynamics of stress propagation along the conveyor belt for various acceleration/deceleration modes is carried out. The calculation of the speed modes of the conveyor section for the Maxwell element elastic element model and the Winkler foundation transport system model is presented in [13]. The elastic Kelvin-Voigt element is used in the model containing the Lagrange equations [14] to calculate the belt stretch curve and velocity curves dependencies. The article [15] examines the models of the elastic element Kelvin-Voigt element, the combination of Hookean and Kelvin-Voigt element, as well as the combination of two Kelvin-Voigt elements. Long-wave oscillations in the conveyor belt for the Hookean element model and the analytical PiKh-model are studied in detail in [16]. The results of experimental studies on the mechanical properties of composite materials for the manufacture of conveyor belts with polyester and polyamide cartridges are given in [17].
Dynamic stress propagation equation. The equation describing the motion of an element $d S$ at a point $S$ on the belt with effective mass $d m$ and acceleration $d \mu(t, S) / d t$ has the form

$$
\frac{d \mu(t, S)}{d t} d m=\sigma(t, S+d S) B h-\sigma(t, S) B h-d F_{W} .
$$

The force of resistance to the movement of the belt $F_{W}$ is the sum of the resistances [16]

$$
F_{W}=F_{H}+F_{N}+F_{S t}+F_{S}
$$

The primary resistances $F_{H}$ assuming a linear relationship between the resistances and the transported load, are determined by

$$
d F_{H}=d S f_{C} g_{m}\left([\chi]_{0 R}+\left([\chi]_{0}(t, S)+[\chi]_{0}\right) \cos \delta_{C}\right),
$$

where $f_{N}$ is the coefficient of rolling resistance of the driving rollers and resistance to indentation of the belt; $g_{m}=9.81(\mathrm{~m} /$ $\left.\mathrm{s}^{2}\right) ;[\chi]_{0 C}$ is linear density of the belt; $[\chi]_{0 R}$ is linear load from rotating parts; $\delta_{C}$ is the angle of inclination of the section of the conveyor. For a conveyor located horizontally, $\cos \delta_{C}=1$.

The force $F_{N}$, taking into account the influence on the movement of the secondary resistances, is expressed in terms of the value of the primary resistances to movement $F_{H}$ (DIN 22101:2002-08)

$$
F_{N}=(C-1) F_{H} .
$$

For extended conveyor systems $C \approx 1.05$. The gradient resistance of the belt and the conveyed material is determined by the expression (DIN 22101:2002-08)

$$
d F_{S t}=d S \sin \delta_{C} g_{m}\left([\chi]_{0}(t, S)+[\chi]_{0 C}\right) .
$$

For horizontally located sections, it is absent, $\sin \delta_{C}=0$. For most conveyor sections, it is assumed that the force $F_{S}$, associated with special resistances, determined by the design of the conveyor, is small $F_{S} \ll F_{H}$. Taking these assumptions into account, let us write the expression for the force of resistance to the movement of the speed in the form

$$
d F_{W}=d S C f_{C} g_{m}\left([\chi]_{0 R}+[\chi]_{0}(t, S)+[\chi]_{0 C}\right) .
$$

The effective mass $d m$ of an element $d S$ at a point $S$ on the conveyor belt is determined through the effective density $[\chi]_{e f}(t, S)$ of the driving element

$$
d m=[\chi]_{e f}(t, S) d S ; \quad[\chi]_{0 e f}(t, S)=[\chi]_{0 R}+[\chi]_{0}(t, S)+[\chi]_{0},
$$

which allows us to write the original equation of motion of an element $d S$ at a point $S$ on the belt in the form

$$
\frac{d \mu(t, S)}{d t}=\frac{B h}{[\chi]_{0 e f}(t, S)} \frac{\partial \sigma(t, S)}{\partial S}-C f_{\tilde{N}} g_{m} .
$$

Let us introduce the absolute elongation of the conveyor belt $W(t, S)$ at the time for the coordinate $S$. The ratio of the elongation $d W(t, S)$ to the length of the segment $d S$ is the relative deformation of the element

$$
\varepsilon(t, S)=\frac{\partial W(t, S)}{\partial S} ; \quad \varepsilon(t, S) \approx 10^{-2}, \quad d S \gg d W(t, S) .
$$

The speed $\mu(t, S)$ of the conveyor belt with the material, consists of the speed of the belt in equilibrium $\mu_{\psi}(t)$ and the oscillating part

$$
\begin{aligned}
\mu(t, S)= & \mu_{\psi}(t)+\frac{d W(t, S)}{d t} ; \quad|\mu(t, S) \varepsilon(t, S)| \ll\left|\frac{\partial W(t, S)}{\partial t}\right| ; \\
& \frac{d W(t, S)}{d t}=\frac{\partial W(t, S)}{\partial t}+\mu(t, S) \varepsilon(t, S),
\end{aligned}
$$

whence follows

$$
\mu(t, S) \approx \mu_{\psi}(t)+\frac{\partial W(t, S)}{\partial t} .
$$


When the length of a segment $d S$ of the transport route changes, the effective density $[\chi]_{0 e f}=[\chi]_{0 e f}(t, S)$ changes. Let the length of the segment change and become equal $(d S+$ $+d W(t, S))$. In this case, the effective density $[\chi]_{0 e f}$ will change and become equal $[\chi]_{0 e f}+\Delta[\chi]_{0 e f}$. Then, for a given section of the transport route, we have the ratio

$$
d S[\chi]_{0 e f}=(d S+d W(t, S))\left([\chi]_{0 e f}+\Delta[\chi]_{0 e f}\right) .
$$

Neglecting a quantity of the order of smallness $d W \Delta[\chi]_{0 e f}$, we obtain

$$
|\partial W(t, S) / \partial S| \approx\left|\partial \Delta[\chi]_{0 e f} /[\chi]_{0 e f}\right| \approx \varepsilon,
$$

which allows the expression for the effective linear density

$$
[\chi]_{0 e f}(t, S) \approx[\chi]_{0 \psi e f}(t, S)(1+\varepsilon) \approx[\chi]_{0 \psi e f}(t, S),
$$

to be written in terms of the linear effective density $[\chi]_{0 \psi e f}$ in the absence of dynamic stresses. Taking these assumptions into account, let us represent $(1,2)$ as follows

$$
\begin{gathered}
\frac{\partial \sigma(t, S)}{\partial t}+\frac{E}{\eta} \sigma(t, S)=E \frac{\partial \varepsilon(t, S)}{\partial t} ; \\
\frac{\partial^{2} W(t, S)}{\partial t^{2}}=\frac{B h}{[\chi]_{0 \psi \text { ef }}(t, S)} \frac{\partial \sigma(t, S)}{\partial S}-\tilde{N} f_{\tilde{N}} g_{m}-\frac{d \mu_{\psi}(t)}{d t} .
\end{gathered}
$$

When designing $(3,4)$, assume that it is unacceptable for the function $\sigma(t, S), \varepsilon(t, S)$ to have a large gradient leading to the destruction of the belt

$$
\frac{\partial \sigma(t, S)}{\partial S} \mu \ll \frac{\partial \sigma(t, S)}{\partial t} ; \quad \frac{\partial \varepsilon(t, S)}{\partial S} \mu \ll \frac{\partial \varepsilon(t, S)}{\partial t} .
$$

Let us integrate (3) over $t$

$$
\sigma(t, S)+\frac{E}{\eta} \int \sigma(t, S) d t=E \varepsilon(t, S)+\sigma_{0}(S) .
$$

Case $E / \eta \rightarrow 0$ conforms to Hooke's law

$$
\sigma(t, S)=E \varepsilon(t, S),
$$

from where $\sigma_{0}(S)=0$. Substituting (5) into equation (4), we obtain

$$
\begin{gathered}
\frac{\partial^{2} W(t, S)}{\partial t^{2}}+\frac{C_{\psi}^{2}(t, S)}{\eta} \int \frac{\partial \sigma(t, S)}{\partial S} d t+C f_{\tilde{N}} g_{m}+\frac{d \mu_{\psi}(t)}{d t}= \\
=C_{\psi}^{2}(t, S) \frac{\partial \varepsilon(t, S)}{\partial S} \\
C_{\psi}^{2}(t, S)=B h E /[\chi]_{0 \psi e f}(t, S),
\end{gathered}
$$

where $C_{\psi}$ is the speed of propagation of disturbances along the conveyor belt [26]. By integrating the expression

$$
\begin{gathered}
\frac{B h}{[\chi]_{0 \psi e f}(t, S)} \int \frac{\partial \sigma(t, S)}{\partial S} d t= \\
=\frac{\partial W(t, S)}{\partial t}-\frac{\partial W(0, S)}{\partial t}+\tilde{N} f_{\tilde{N}} g_{m} t+\mu_{\psi}(t)-\mu_{\psi}(0),
\end{gathered}
$$

we obtain a wave equation for describing longitudinal vibrations in a conveyor belt

$$
\begin{gathered}
\frac{\partial^{2} W(t, S)}{\partial t^{2}}+\frac{1}{t_{0}}\left(\frac{\partial W(t, S)}{\partial t}-\left.\frac{\partial W(t, S)}{\partial t}\right|_{t=0}\right)= \\
=-C f_{C} g_{m}\left(\frac{t}{t_{0}}+1\right)-\frac{\mu_{\psi}(t)-\mu_{\psi}(0)}{t_{0}}-\frac{d \mu_{\psi}(t)}{d t}+ \\
+C_{\psi}^{2}(t, S) \frac{\partial^{2} W(t, S)}{\partial S^{2}} .
\end{gathered}
$$

Boundary and initial conditions. Let us supplement equation (6) with boundary conditions (Fig. 3)

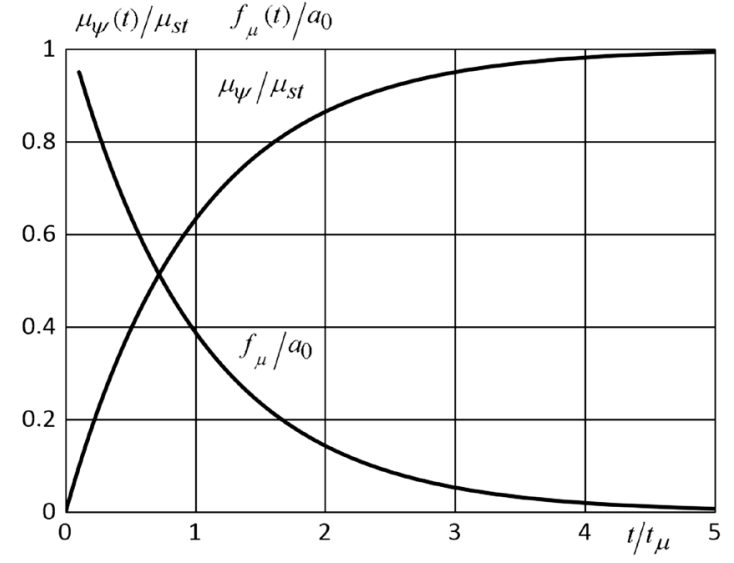

Fig. 3. Conveyor belt speed and acceleration

$$
\left.\frac{\partial W(t, S)}{\partial S}\right|_{S=0}=\frac{T_{4}}{E B h} ;\left.\quad \frac{\partial W(t, S)}{\partial S}\right|_{S=S_{d}}=\frac{T_{1}}{E B h} .
$$

The tension force $T_{4}$ is determined from the condition

under dynamic load

$$
T_{4}+T_{3}=T_{0} ; \quad T_{4}=k_{s} T_{3},
$$

$$
T_{0}=M_{w} g_{m}+M_{w} \frac{\partial^{2} W(t, 0)}{\partial t^{2}},
$$

where $M_{w}$ is the weight of the suspended load, which ensures the pretension of the belt. For transport conveyors, the drum loss factor " $A$ " is $k_{s} \approx 1.03$. Using the ratio

$$
T_{4}+\frac{1}{k_{s}} T_{4}=M_{w} g_{m}+M_{w} \frac{\partial^{2} W(t, 0)}{\partial t^{2}},
$$

let us write down the first boundary condition

$$
\left.\frac{\partial W(t, S)}{\partial S}\right|_{S=0}=\frac{k_{s}}{k_{s}+1} \frac{M_{w}}{E B h}\left(g_{m}+M_{w} \frac{\partial^{2} W(t, 0)}{\partial t^{2}}\right) .
$$

If the acceleration of the suspended load is small and, assuming, $k_{s} /\left(k_{s}+1\right) \approx 0.5$, the boundary condition can be represented in the form

$$
\frac{\partial^{2} W(t, 0)}{\partial t^{2}}=\frac{M_{w} g_{m}}{2 E B h} .
$$

To construct the second boundary condition that determines the tension force $T_{1}$ of a conveyor equipped with an asynchronous motor with a phase rotor, we will use the relationship between the tractive torque and the angular speed of rotation, for a given mechanical characteristic of the electric motor (Fig. 1). For the range $n_{\text {eng }} / n_{\text {eng } 0} \in[0.0 ; 0.4]$ let us define the relationship between the tractive torque and the rotor speed with the mechanical characteristic shown in Fig.1

$$
\frac{M_{\text {eng }}}{M_{\text {eng } 0}}=a-b \frac{n_{\text {eng }}}{n_{\text {eng } 0}}, \quad a=1.6, b=1.0 .
$$

Let us represent the last equation in the form

$$
\frac{T_{1}-T_{2}}{M_{\text {eng } 0} / r}=a-b \frac{\mu_{\psi}(t)}{\mu_{0}} ; \quad T_{1}-T_{2}=M_{\text {eng }} / r,
$$

where the standard speed of the belt $\mu_{0}=n_{\text {eng } 0} 2 \pi r$ corresponds to the standard speed of rotation of the rotor $n_{\text {eng } 0} \mathrm{c}$ with a drum radius $r$. The tensile force $T_{1}$ is determined from the system of equations

$$
\left\{\begin{array}{l}
T_{1}=T_{2} \exp \left(k_{b} \alpha\right), \quad T_{4}=k_{s} T_{3} \\
T_{3}=T_{2}+F_{H(2-3)}+F_{N(2-3)}+F_{\psi(2-3)}, \\
T_{1}=T_{4}+F_{H(4-1)}+F_{N(4-1)}+F_{\psi(4-1)}
\end{array}\right.
$$


where $k_{b}$ is the coefficient of adhesion between the drum and the belt. The values of these functions for the intervals specified by the points of application of forces $T_{1}, T_{2}, T_{3}, T_{4}$ are determined by the expressions

$$
\begin{gathered}
F_{H 23}=S_{d} f_{C} g_{m}\left([\chi]_{0 R}+[\chi]_{0 C}\right) ; \quad F_{N 23}=(C-1) F_{H 23} ; \\
F_{\psi 23}=\int_{0}^{S_{d}} \frac{d \mu}{d t}\left([\chi]_{0 R}+[\chi]_{0 C}\right) d S=f_{\psi}(t)\left([\chi]_{0 R}+[\chi]_{0 C}\right) S_{d} ; \\
F_{H 41}=F_{H 23}+f_{C} g_{m} \int_{0}^{S_{d}}[\chi]_{0}(t, S) d S ; \\
F_{N 41}=(C-1) F_{H 41} ; \quad F_{\psi 41}=F_{\psi 23}+\int_{0}^{S_{d}} \frac{d \mu}{d t}[\chi]_{0}(t, S) d S .
\end{gathered}
$$

During the characteristic time of acceleration of the conveyor belt $\Delta T_{f}$ material travels a path $\Delta T_{f} \mu_{0} \ll S_{d}$, which makes it possible to consider the value $M$ as slowly changing over time

$$
\int_{0}^{S_{d}}[\chi]_{0}(t, S) d S=M ; \quad \frac{M}{t_{\mu}} \gg \frac{d M}{d t} .
$$

Since the speed of the belt is much less than the speed of propagation of disturbances, it follows

$$
\int_{0}^{t_{\mu}} \int_{0}^{S_{d}} \frac{d \mu}{d t}[\chi]_{0}(t, S) d S d t \approx M \int_{0}^{t_{\mu}} f_{\psi}(t) d t .
$$

The solution to system (8) gives an expression for the tensile force $T_{1}$

$$
T_{1}=\left(k_{s} C F_{H 23}+k_{s} F_{\psi 23}+C F_{H 41}+F_{\psi 41}\right) \frac{\exp \left(k_{b} \alpha\right)}{\exp \left(k_{b} \alpha\right)-k_{s}} .
$$

Using (7), let us obtain the second boundary condition

$$
\begin{gathered}
\left.\frac{\partial W(t, S)}{\partial S}\right|_{S=S_{d}}=\frac{T_{1}}{E B h}=a_{w}-b_{w} \mu_{\psi}(t) ; \\
a_{w}=\frac{M_{\text {eng } 0}}{r} \frac{\exp \left(k_{b} \alpha\right)}{\exp \left(k_{b} \alpha\right)-1} \frac{a}{E B h} ; \quad b_{w}=\frac{a_{w}}{a} \frac{b}{\mu_{0}} .
\end{gathered}
$$

Boundary condition (9) depends on the linear speed of rotation of the drum $\mu_{w}(t)$. To determine the magnitude of the speed $\mu_{\psi}(t)$ let us use (7). Let us introduce the coefficients

$$
\begin{gathered}
c_{w 1}=\frac{k_{s}+1}{E B h} \frac{\exp \left(k_{b} \alpha\right)}{\exp \left(k_{b} \alpha\right)-k_{s}} C f_{C} g_{m}\left([\chi]_{0 R}+[\chi]_{0 C}\right) S_{d} ; \\
c_{w 2}=\frac{1}{E B h} \frac{\exp \left(k_{b} \alpha\right)}{\exp \left(k_{b} \alpha\right)-k_{s}} C f_{C} g_{m} M \\
d_{w 1}=\frac{k_{s}+1}{E B h} \frac{\exp \left(k_{b} \alpha\right)}{\exp \left(k_{b} \alpha\right)-k_{s}}\left([\chi]_{0 R}+[\chi]_{0 C}\right) S_{d} ; \\
d_{w 2}=\frac{1}{E B h} \frac{\exp \left(k_{b} \alpha\right)}{\exp \left(k_{b} \alpha\right)-k_{s}} M \\
a_{0}=\frac{a_{w}-c_{w 1}-c_{w 2}}{d_{w 1}+d_{w 2}} ; \quad b_{0}=\frac{b_{w}}{d_{w 1}+d_{w 2}}
\end{gathered}
$$

then (9) takes the form

$$
\frac{d \mu_{\psi}(t)}{d t}=a_{0}-b_{0} \mu_{\psi}(t), \quad \mu_{\psi}(0)=0
$$

For long conveyor systems, during the characteristic acceleration (deceleration) time $t_{\mu}$ the mass of the transported cargo is a quasi-stationary value, which allows us to count $a_{0}=$ $=$ const, $b_{0}=$ const during the acceleration process. The solution to the last equation has the form

$$
\mu_{\psi}(t)=\frac{a_{0}}{b_{0}}\left(1-e^{-b_{0} t}\right) ; \quad t_{\mu}=b_{0}^{-1} ;
$$

$$
\mu_{s t}=\mu_{\psi}(\infty)=\frac{a_{0}}{b_{0}}=\frac{a_{w}-c_{w 1}-c_{w 2}}{b_{w}}=\frac{a}{b} \mu_{0}-\frac{C f_{C} g_{m}}{b_{0}} .
$$

The characteristic acceleration time during which the conveyor belt with the material reaches the value of the standard speed $\mu_{0}$ at the standard value of the traction moment $M_{\text {eng } 0}$, can be estimated by the value

$$
\begin{gathered}
t_{\mu}^{-1}=\left.b_{0}\right|_{k_{s} \rightarrow 1}=\frac{M_{\text {eng } 0}}{r} \frac{b}{2 \pi r n_{\text {eng } 0}} \frac{1}{M_{\mu}} ; \\
M_{\mu}=2\left([\chi]_{0 R}+[\chi]_{0 C}\right) S_{d}+M .
\end{gathered}
$$

The solution $\mu_{w}(t)$ is shown in Fig. 3. The conveyor belt reaches speed $\mu_{s t}$ for time $t \approx 5 t_{\mu}$. The acceleration of the tape has a maximum value in the interval $t \in\left[0, t_{\mu}\right]$. After a period of time $t \approx 5 t_{\mu}$ the movement of the belt becomes uniform. There is no acceleration at belt speed $\mu_{s t}$. If the speed $\mu_{s t}$ is less or more than the required value of the standard speed of the conveyor line, then a change in the value $\mu_{s t}$ can be achieved through a decrease or increase in engine power as a result of switching the power mode (Fig. 1). Let us supplement equation (6) with the initial conditions

$$
\begin{gathered}
\frac{\partial W(0, S)}{\partial S}=\left.\frac{1}{E B h}\left(T_{4}+\frac{T_{1}-T_{4}}{S_{d}} S\right)\right|_{t=0}= \\
=\frac{k_{s}}{k_{s}+1} \frac{M_{w} g_{m}}{E B h}+\left.\left(a_{w}-b_{w} \mu_{\psi}(t)-\frac{k_{s}}{k_{s}+1} \frac{M_{w} g_{m}}{E B h}\right) \frac{S}{S_{d}}\right|_{t=0} ; \\
\left.\frac{\partial W(t, S)}{\partial t}\right|_{t=0}=0 .
\end{gathered}
$$

For positions $S=0, S=S_{d}$ the initial conditions correspond to the boundary

$$
\left.\frac{\partial W(t, S)}{\partial S}\right|_{\substack{t=0 \\ S=0}}=\left.\frac{T_{4}}{E B h}\right|_{t=0} ;\left.\quad \frac{\partial W(t, S)}{\partial S}\right|_{\substack{t=0 \\ S=S_{d}}}=\left.\frac{T_{1}}{E B h}\right|_{\substack{t=0 \\ S=S_{d}}} .
$$

Analysis of the solution of the dynamic stress propagation equation. When constructing the solution, we will assume that the characteristic time of the process $t_{w}$ is much less than the time $t_{0}$, during which a significant decrease in tension occurs (Maxwell element)

$$
\varepsilon_{w}=t_{w} / t_{0} \ll 1, \quad t \in\left[0, t_{w}\right] .
$$

If this condition is not met, the conveyor belt within a short operating time would receive a significant elongation, which would lead to a stop of the conveyor. Let us also assume that the material is uniformly distributed along the transport route with density $[\chi]_{0 \text { wef }}$ and the speed of the conveyor belt at the initial moment of time is equal to zero. Then the dynamic stress propagation equation (6) can be represented as

$$
\begin{gathered}
\frac{\partial^{2} W(t, S)}{\partial t^{2}}-C_{\psi 0}^{2} \frac{\partial^{2} W(t, S)}{\partial S^{2}}+\frac{d \mu_{\psi}(t)}{d t}+C f_{C} g_{m}= \\
=-\varepsilon_{w}\left(\frac{1}{t_{w}} \frac{\partial W(t, S)}{\partial t}+C f_{C} g_{m} \frac{t}{t_{w}}+\frac{\mu_{\psi}(t)}{t_{w}}\right),
\end{gathered}
$$

with boundary conditions

$$
\begin{gathered}
\left.\frac{\partial W(t, S)}{\partial S}\right|_{S=0}=\frac{k_{s}}{k_{s}+1} \frac{M_{w}}{E B h}\left(g_{m}+\frac{\partial^{2} W(t, 0)}{\partial t^{2}}\right) ; \\
\left.\frac{\partial W(t, S)}{\partial S}\right|_{S=S_{d}}=a_{w}-b_{w} \mu_{\psi}(t),
\end{gathered}
$$

and initial conditions

$$
\frac{\partial W(0, S)}{\partial S}=\frac{k_{s}}{k_{s}+1} \frac{M_{w} g_{m}}{E B h}\left(1-\frac{S}{S_{d}}\right)+a_{w} \frac{S}{S_{d}} ;\left.\quad \frac{\partial W(t, S)}{\partial t}\right|_{t=0}=0
$$




$$
\mu_{\psi}(t)=\frac{a_{0}}{b_{0}}\left(1-e^{-b_{0} t}\right), \quad \mu_{\psi}(0)=0 .
$$

Let us represent the solution of equation (10) in the form

$$
W(t, S)=W_{0}(t, S)+W_{1}(t, S)+\ldots+W_{n}(t, S) .
$$

Substituting series (11) into equation (10) and equating the coefficients at the same powers of the parameter $\varepsilon_{w}$, we obtain the system of equations

$$
\begin{gathered}
\frac{\partial^{2} W_{0}(t, S)}{\partial t^{2}}-C_{\psi 0}^{2} \frac{\partial^{2} W_{0}(t, S)}{\partial S^{2}}=-C f_{C} g_{m}-\frac{d \mu_{\psi}(t)}{d t} ; \\
\frac{\partial^{2} W_{1}(t, S)}{\partial t^{2}}-C_{\psi 0}^{2} \frac{\partial^{2} W_{1}(t, S)}{\partial S^{2}}= \\
=-\frac{1}{t_{w}} \frac{\partial W_{0}(t, S)}{\partial t}-C f_{\tilde{N}} g_{m} \frac{t}{t_{w}}-\frac{\mu_{\psi}(t)}{t_{w}} ; \\
\frac{\partial^{2} W_{k}(t, S)}{\partial t^{2}}-C_{\psi 0}^{2} \frac{\partial^{2} W_{k}(t, S)}{\partial S^{2}}=-\frac{\partial W_{k-1}(t, S)}{t_{w} \partial t}, \quad k=2 . . n .
\end{gathered}
$$

Let us dwell on the solution of the first equation, which is determined by the zero approximation in the parameter $\varepsilon_{w}$. Let us look for a solution in the form

$$
\begin{gathered}
W_{0}(t, S)=V_{S}(t, S)+V(t, S) \\
V_{S}(t, S)=\frac{k_{s}}{k_{s}+1} \frac{M_{w} g_{m}}{E B h} S+\left(a_{w}-b_{w} \mu_{\psi}(t)-\frac{k_{s}}{k_{s}+1} \frac{M_{w} g_{m}}{E B h}\right) \frac{S^{2}}{2 S_{d}} .
\end{gathered}
$$

The function $V_{S}(t, S)$ determines the static deflection of the belt in the absence of dynamic stresses (undisturbed state of the conveyor belt). The function $V(t, S)$ is the deviation from the undisturbed state. Let us introduce the notation

$$
\begin{gathered}
A_{m 0}=\frac{1}{E B h} \frac{M_{\text {eng } 0}}{r} \frac{\exp \left(k_{b} \alpha\right)}{\left(\exp \left(k_{b} \alpha\right)-1\right)} ; \\
A_{0}=\left(\frac{a}{a_{w}}\right) \frac{k_{s}}{k_{s}+1} \frac{M_{w} g_{m}}{E B h}=\frac{k_{s}}{k_{s}+1} \frac{M_{w} g_{m}}{\frac{M_{e n g 0}}{r} \frac{\exp \left(k_{b} \alpha\right)}{\left(\exp \left(k_{b} \alpha\right)-1\right)}},
\end{gathered}
$$

taking into account which, let us write down the expression for the magnitude of stresses in the undisturbed state

$$
\frac{a}{a_{w}} \frac{\partial V_{S}(t, S)}{\partial S}=A_{0}\left(1-\frac{S}{S_{d}}\right)+\left(a-b \frac{\mu_{s t}}{\mu_{0}}\left(1-e^{-b_{0} t}\right)\right) \frac{S}{S_{d}} .
$$

Function graph $Q\left(t / t_{\mu}\right) Q\left(t / t_{\mu}\right)$

$$
Q\left(t / t_{\mu}\right)=\left.\left(\frac{a}{a_{w}}\right) \frac{\partial V_{S}(t, S)}{\partial S}\right|_{S=S_{d}}=a-b \frac{\mu_{s t}}{\mu_{0}}\left(1-e^{-t / t_{\mu}}\right),
$$

characterizing the stress at a point $S=S_{d}$ for values $\mu_{s t} / \mu_{0}=$ $=\{0.1 ; 0.2 ; 0.3 ; 0.4\}$ при $a=1.6, b=1.0$ (7) is shown in Fig. 4 . The relative stress $Q\left(t / t_{\mu}\right)$ decreases exponentially, reaching a constant value according to equation (7). The relative stresses shown in Fig. 4 for the undisturbed state correspond to the range of variation of the belt speed $\mu_{\text {eng }} / \mu_{\text {eng } 0} \in[0.0 ; 0.4]$ and the magnitude of the traction moment $M_{\text {eng }} / M_{\text {eng } 0} \in[1.6 ; 1.2]$.

Substituting solution (13) into the equation for the zero approximation $\varepsilon_{w}(12)$ and taking this into account

$$
\begin{gathered}
C_{\psi 0}^{2} \frac{\partial^{2} V_{S}(t, S)}{\partial S^{2}}=C f_{\tilde{N}} g_{m}+\frac{d \mu_{\psi}(t)}{d t} \\
\frac{\partial V_{S}(t, S)}{\partial S}=\frac{k_{s}}{k_{s}+1} \frac{M_{w} g_{m}}{E B h}+\left(a_{w}-b_{w} \mu_{\psi}(t)-\frac{k_{s}}{k_{s}+1} \frac{M_{w} g_{m}}{E B h}\right) \frac{S}{S_{d}} \\
\frac{\partial^{2} V_{S}(t, S)}{\partial t^{2}} \approx\left(\frac{S_{d} / t_{\mu}}{C_{\psi 0}}\right)^{2} \frac{d \mu_{\psi}}{d t}
\end{gathered}
$$

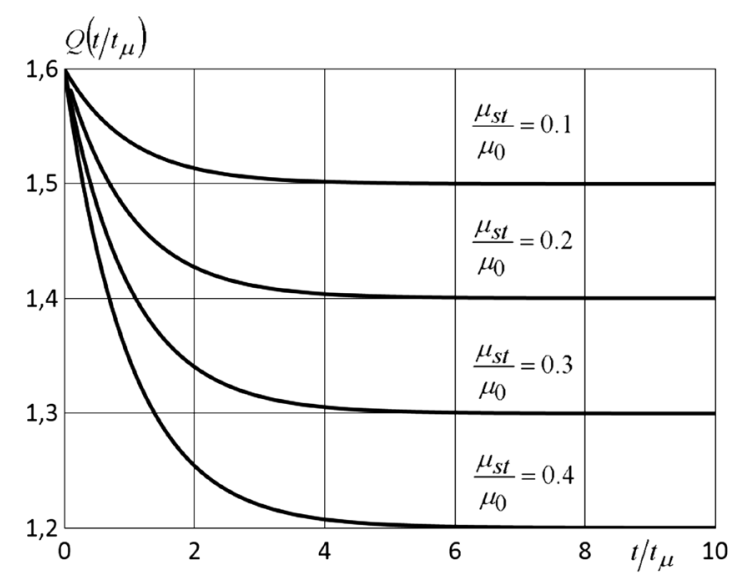

Fig. 4. Relative stress of the conveyor belt in the absence of $d y$ namic stress

we obtain the system of equations for the function $V(t, S)$

$$
\frac{\partial^{2} V(t, S)}{\partial t^{2}}=C_{\psi 0}^{2} \frac{\partial^{2} V(t, S)}{\partial S^{2}}
$$

with boundary conditions

$$
\left.\frac{\partial V(t, S)}{\partial S}\right|_{S=0}=\frac{k_{s}}{k_{s}+1} \frac{M_{w}}{E B h} \frac{\partial^{2} V(t, 0)}{\partial t^{2}} ;\left.\quad \frac{\partial V(t, S)}{\partial S}\right|_{S=S_{d}}=0,
$$

and initial conditions

$$
\frac{\partial V(0, S)}{\partial S}=0 ;\left.\quad \frac{\partial V(t, S)}{\partial t}\right|_{t=0}=b_{w} a_{0} \frac{S^{2}}{2 S_{d}} .
$$

When deriving (14), it was assumed that the material is uniformly distributed along the route ( $C_{\psi 0}$ is constant)

$$
C_{\psi 0}^{2} \frac{\partial^{2} V_{S}(t, S)}{\partial S^{2}} \gg \frac{\partial^{2} V_{S}(t, S)}{\partial t^{2}} \approx\left(\frac{S_{d} / t_{\mu}}{C_{\psi 0}}\right)^{2} \frac{d \mu_{\psi}}{d t} .
$$

The relationship $S / t_{\mu}$ for the various conveyors in operation is presented in the Table. The speed of propagation of disturbances was estimated as $C_{\psi 0} \approx 2000 \mathrm{~m} / \mathrm{s}$. This implies

$$
\left(S_{d} / t_{\mu} / C_{\psi 0}\right)^{2} \approx(60 / 2000)^{2} \approx 0.001 .
$$

Let us first of all dwell on the study on the natural frequencies of stress oscillations arising in the conveyor belt. To do this, let us find a solution to the problem posed, presented in the form

$$
V(t, S)=T(t) X(S) \text {. }
$$

Substituting $V(t, S)$ into (14) and using the boundary conditions, we obtain after separation of variables for the amplitude of standing waves

$$
\frac{d^{2} X_{n}(S)}{d S^{2}}+\lambda_{n}^{2} X_{n}(S)=0
$$

Table

Conveyor belt acceleration mode time

\begin{tabular}{|l|c|c|c|}
\hline \multicolumn{1}{|c|}{ Conveyor name } & $\begin{array}{c}S_{d}, \\
\mathrm{~m}\end{array}$ & $\begin{array}{c}t_{\mu}, \\
\mathrm{S}\end{array}$ & $\frac{S_{d}}{t_{\mu}}$ \\
\hline Conveyor at the Zimbabwe Iron \& Steel Co & 15600 & 500 & 31.2 \\
\hline Conveyor C3, Indo Kodeco System Layout & 8600 & 250 & 34.4 \\
\hline North Shaft decline conveyor & 1350 & 30 & 45.0 \\
\hline Experimental conveyor [18] & 3620 & 60 & 61.0 \\
\hline Conveyor CV002B, El Brocal [19] & 2781 & 80 & 34.8 \\
\hline
\end{tabular}




$$
X_{n}(S)=\sin \left(\lambda_{n} S_{d}\right)\left(\sin \left(\lambda_{n} S\right)+B_{n} \cos \left(\lambda_{n} S\right)\right),
$$

with boundary conditions

$$
\begin{gathered}
\left.\frac{\partial X_{n}(S)}{\partial S}\right|_{S=0}=-c_{0} \lambda_{n}^{2} X(t, 0) ; \quad c_{0}=C_{\psi 0}^{2} \frac{k_{s}}{k_{s}+1} \frac{M_{w}}{E B h} \\
\left.\frac{\partial X_{n}(S)}{\partial S}\right|_{S=S_{d}}=0 .
\end{gathered}
$$

From the boundary conditions let us find

$$
\begin{gathered}
1=-c_{0} \lambda_{n} B_{n} ; \quad \operatorname{ctg}\left(\lambda_{n} S_{d}\right)=B_{n} ; \\
\operatorname{tg}\left(\lambda_{n} S_{d}\right)=-c_{0} \lambda_{n},
\end{gathered}
$$

from where

$$
X_{n}(S)=\cos \left(\lambda_{n} S-\lambda_{n} S_{d}\right) .
$$

The orthogonality conditions for the functions $X_{n}(S)$ take the form

$$
\begin{gathered}
\int_{0}^{S_{d}} X_{n}(S) X_{m}(S) d S+c_{0} X_{n}(0) X_{m}(0)=0 \\
\left\|X_{n}^{2}\right\|=\int_{0}^{S_{d}} X_{n}^{2}(S) d S+c_{0} X_{n}^{2}(0) .
\end{gathered}
$$

Let us seek a solution to the problem (14) in the form of an expansion along the axis $S$

$$
V(t, S)=\sum_{n=1}^{\infty} T_{n}(t) \cos \left(\lambda_{n} y\right), \quad y=S-S_{d},
$$

while considering time $t$ as a parameter. The value $\lambda_{n}$ is found from the solution of the transcendental equation. Using the initial conditions

$$
\begin{gathered}
\left.\frac{\partial V(t, S)}{\partial S}\right|_{t=0}=-\lambda_{n} \sum_{n=1}^{\infty} T_{n}(0) \lambda_{n} \sin \left(\lambda_{n} y\right)=0 ; \\
\left.\frac{\partial V(t, S)}{\partial t}\right|_{t=0}=b_{w} a_{0} \frac{S^{2}}{2 S_{d}}=\sum_{n=1}^{\infty} \frac{d T_{n}(0)}{d t} \cos \left(\lambda_{n} y\right),
\end{gathered}
$$

let us define

$$
T_{n}(0)=0 ; \quad \frac{d T_{n}(0)}{d t}=\frac{1}{\left\|X_{n}^{2}\right\|_{-S_{d}}^{0}} \cos \left(\lambda_{n} y\right)\left(y+S_{d}\right)^{2} d y .
$$

For the case where the weight of the gravity weight is very large compared to the weight to be moved

fair equality

$$
M_{w} \gg[\chi]_{0 \psi e f 0} S_{d},
$$

$$
c_{0} \lambda_{n} \gg 1
$$

which allows conditions (15) to be written in the form

$$
\operatorname{ctg}\left(\lambda_{n} S_{d}\right) \rightarrow 0 .
$$

From the last relation, it follows

$$
B_{n}=0 ; \quad \lambda_{n}=\frac{\pi}{S_{d}}(n-1 / 2), \quad X_{n}(0)=0 .
$$

The resulting boundary condition corresponds to the case of rigid fixation at a point $S=0$. The solution $X_{n}(S), V(t, S)$ for the considered case will be sought in the form

$$
X_{n}(S)=\sin \left(\lambda_{n} S\right) ; \quad V(t, S)=\sum_{n=1}^{\infty} T_{n}(t) \sin \left(\lambda_{n} S\right),
$$

where the initial conditions for $T_{n}(t)$ are determined from the system of equations

$$
\frac{\partial V(0, S)}{\partial S}=0 ;\left.\quad \frac{\partial V(t, S)}{\partial t}\right|_{t=0}=\sum_{n=1}^{\infty} \frac{d T_{n}(0)}{d t} \sin \left(\lambda_{n} S\right) .
$$

Using the Fourier series expansions, let us obtain

$$
T_{n}(0)=0 ; \quad \frac{d T_{n}(0)}{d t}=b_{w} a_{0} S_{d}\left(\frac{(-1)^{n-1}}{\pi n-\pi / 2}-\frac{1}{(\pi n-\pi / 2)^{2}}\right) .
$$

The solution to the equation for given initial conditions has the form

$$
\begin{gathered}
T_{n}(t)=c_{n} \sin \left(\omega_{n} t\right) ; \\
\omega_{n}=C_{\psi 0} \frac{\pi}{S_{d}}\left(n-\frac{1}{2}\right) ; \quad c_{n}=\frac{1}{\omega_{n}} \frac{d T_{n}(0)}{d t} .
\end{gathered}
$$

The solution that determines the dynamic tension of the conveyor belt is presented in the form

$$
V(t, S)=\sum_{n=1}^{\infty} c_{n} \sin \left(\omega_{n} t\right) \sin \left(\lambda_{n} S\right) .
$$

The total tension in the conveyor belt is determined by the expression

$$
\frac{\partial W_{0}(t, S)}{\partial S}=\frac{\partial V_{S}(t, S)}{\partial S}+\frac{\partial V(t, S)}{\partial S}
$$

Using the notation $A_{0}, a_{w}$, $a$, let us consider the propagation of dynamic stresses for $n=1$.

$$
\begin{gathered}
Q_{1}(\tau, \xi)=\left.\frac{a}{A_{0} a_{w}} \frac{\partial W_{0}(t, S)}{\partial S}\right|_{n=1}=\frac{B_{0}}{A_{0}} \sin \left(\omega_{w} \tau\right) \cos \left(\lambda_{w} \xi\right)+ \\
+(1-\xi)+\left(\frac{a}{A_{0}}-\frac{b}{A_{0}} \frac{\mu_{s t}}{\mu_{0}}(1-\exp (-\tau))\right) \xi ; \\
B_{0}=0.64 \frac{S_{d} b}{C_{\psi 0} t_{\mu}} \frac{\mu_{s t}}{\mu_{0}} ; \quad \xi=\frac{S}{S_{d}} ; \quad \tau=\frac{t}{t_{\mu}} ; \\
\omega_{w}=\omega_{1} t_{\mu} \approx 1.57 C_{\psi 0} t_{\mu} / S_{d} ; \quad \lambda_{w}=\lambda_{1} S_{d} \approx 1.57 .
\end{gathered}
$$

An estimated calculation shows that for the acceleration modes presented in the Table, $A_{0} \gg B_{0}$, and, therefore, the dynamic stresses in the conveyor belt will be significantly less than the static stress. Estimation of the characteristic acceleration time at which $A_{0} \approx B_{0}$, is determined by the expression

$$
t_{\mu} \approx \frac{1}{A_{0}} \frac{S_{d}}{C_{\psi 0}} \frac{\mu_{s t}}{\mu_{0}} ; \quad \omega_{w}=\omega_{1} t_{\mu} \approx \frac{1.57}{A_{0}} \frac{\mu_{s t}}{\mu_{0}} .
$$

For the values $S_{d} \approx 10000, C_{\psi 0} \approx 2000, A_{0} \approx 10, b \approx A_{0}$, $a \approx 2.5 A_{0}, \mu_{s t} / \mu_{0} \approx 0.4$ it turns out $t_{\mu} \approx 0.1, \omega_{w}=\omega_{1} t_{\mu} \approx \pi, \lambda_{w}=$ $=\pi / 2$, and, accordingly

$$
Q_{1}(\tau, \xi) \approx 1+\xi-0.4(1-\exp (-\tau)) \xi+\sin (\pi \tau) \cos \left(\frac{\pi}{2} \xi\right) .
$$

When $S=S_{d}$, the function $Q_{1}(\tau, \xi)$ goes to the function $Q(\tau) / A_{0}$ (Fig. 4)

$$
Q_{1}(\tau, 1) \approx(2-0.4(1-\exp (\tau))) \xi .
$$

The dynamics of the stresses in the conveyor belt for the case determined by the function $Q_{1}(\tau, \xi)$ are shown in Fig. 5 . A family of curves characterizes the magnitude of the stresses in the conveyor belt at different points in time. At $B_{0} / A_{0}=1$ the stress along the conveyor belt does not exceed the maximum stress value $Q_{1}(0,1)$ at the conveyor belt starts. In subsequent time intervals, a decrease in the stress value in the conveyor belt occurs. The maximum amplitude of stress fluctuations is achieved at the beginning of the conveyor belt $\xi=0$, which can lead to belt sagging effects.

An increase in the ratio $B_{0} / A_{0}$ leads to the occurrence of stresses with a maximum value in the middle of the transport section. The presence of stresses with a maximum value exceeding the stress value $Q_{1}(0,1)$ at the time $\tau=0$ for the boundary point of the conveyor belt $\xi=1$, is shown in Fig. 6 . The analysis of the function $Q_{1}(\tau, \xi)$ allows us to conclude that when the belt is accelerated, the most dangerous is the initial moment of ac- 


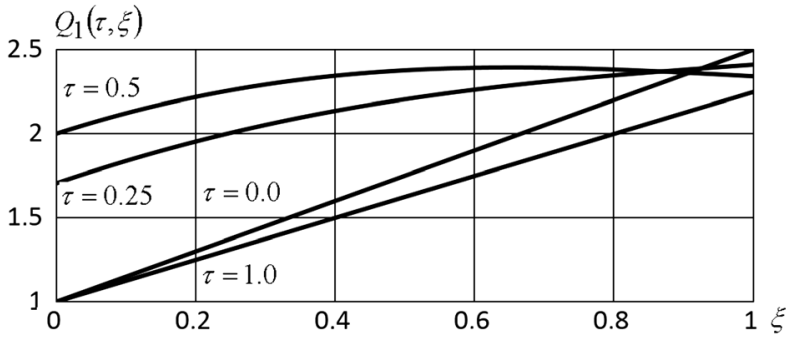

Fig. 5. Relative stress of the conveyor belt in the presence of $d y$ namic stresses $B_{0}=A_{0}$

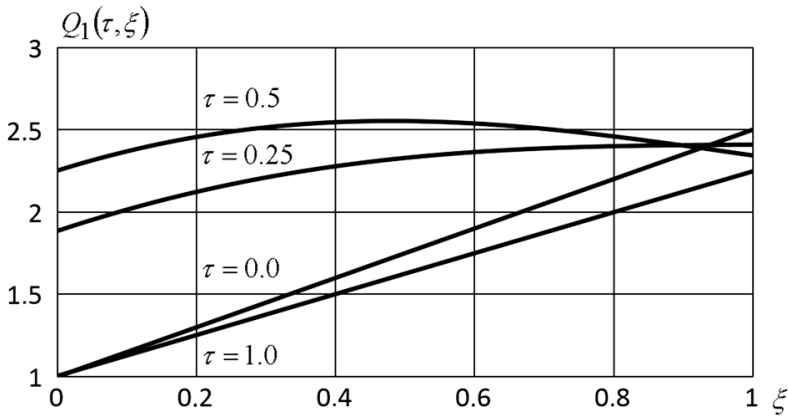

Fig. 6. Relative stress of the conveyor belt in the presence of $d y$ namic stresses $B_{0}=1.25 A_{0}$

celeration, which is determined by the gap $\tau \in[0,1[$. The amplitude of longitudinal vibrations for subsequent periods of time $\tau \in[1,2[, \tau \in[2,3[\ldots$ decreases, which is associated with an increase in the speed of the belt.

An estimate of the decrease in the magnitude of stresses in the transition to the standard value of the speed of the belt $\mu_{s t}$ can be obtained from the analysis of the family of dependencies shown in Fig. 7. For the indicated points in time, there are no dynamic stresses in the conveyor belt. The stresses in the conveyor belt are set by the expression

$$
Q_{1}(\tau, \xi) \approx 1+\xi-0.4(1-\exp (-\tau)) \xi,
$$

which is written taking into account the fact that for the time $\tau=0,1,2, \ldots$, there are no dynamic stresses in the conveyor belt, $\sin (\pi \tau)=0$. A significant decrease in the magnitude of stresses occurs in the initial period of acceleration of the conveyor belt. $\tau \in[0,1[$.

Conclusions. The analysis of the causes of dynamic stresses in the conveyor belt, the material of which corresponds to the Maxwell-element model, is carried out. The value of the characteristic times of the process is determined, for which the influence of material properties is significant. Using the method of successive approximations, a system of equations has been developed that makes it possible to analyze the occurrence of dynamic stresses, considering the specific properties of the material. The propagation of dynamic disturbances, taking into account the features characteristic of the Maxwell-ele-

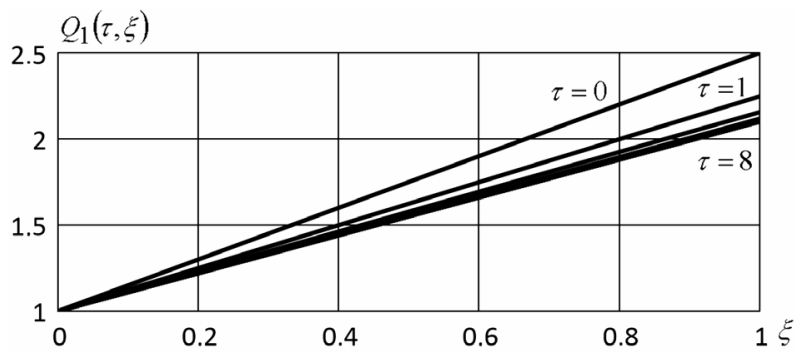

Fig. 7. Relative stress of the conveyor belt in the presence of $d y$ namic stresses $B_{0}=1.25 A_{0}$ ment model, can be investigated in detail for the steady-state mode of operation of the conveyor belt. In this case, the characteristic time of the process significantly exceeds the characteristic time of acceleration or deceleration of the conveyor belt. This allows us to conclude that when analyzing the dynamic stresses arising in the period that determines the process of acceleration or deceleration of a conveyor belt, the effects associated with the behaviour of a material whose properties correspond to the Maxwell-element model are insignificant. For the time interval corresponding to the acceleration time of the conveyor belt, when analyzing the causes of dynamic disturbances, the Hooke element model can be used with a sufficient degree of accuracy. The acceleration time is significantly shorter than the stress relaxation time for a material conforming to the Maxwell-element model.

Another important part of the research is related to the influence of boundary conditions on the process of dynamic stress propagation in a conveyor belt. The case of the propagation of dynamic disturbances is considered when the boundary conditions are set in the form of a dependence that determines the relationship between the traction moments of the induction motor and the speed of the conveyor belt. To tension, the conveyor belt, a mechanism with a load at the entrance to the section is used. The presented analysis of the propagation of dynamic disturbances demonstrates the possibility of the occurrence of maximum permissible stresses along the conveyor section, which can lead to the destruction of the conveyor belt. The magnitude of the stresses is directly related to the magnitude of the characteristic acceleration time of the belt.

The obtained research results provide an opportunity to study the relaxation processes that are provided in the conveyor belt, the material of which corresponds to the Maxwellelement model.

\section{References.}

1. Siemens (2021). SIMINE for conveyors. Retrieved from www.siemens.com/mining.

2. Conveyor Dynamics (2020). Curragh Project. Retrieved from http:// conveyordynamics.com/index.php/project/curragh/.

3. Mathaba, T., \& Xia, X. (2015). A parametric energy model for energy management of long belt conveyors. Energies, 8(12), 1359013608. https://doi.org/10.3390/en81212375.

4. Antonia, J. (2010). Energy-saving belt conveyors installed in polish collieries. Transport Problems, 5(4), 5-14.

5. Halepoto, I., Shaikh, M., \& Chowdhry, B. (2016). Design and Implementation of Intelligent Energy Efficient Conveyor System Model Based on Variable Speed Drive Control and Physical Modeling. Control and Physical Modeling. Journal of Control and Automation, 9(6), 379-388.

6. Pihnastyi, O., \& Khodusov, V. (2019). The optimal control problem for output material flow on conveyor belt with input accumulating bunker. Bulletin of the South Ural State University. Ser Mathematical Modelling, Programming \& Computer Software (Bulletin SUSUMMCS), 12(2), 67-81. https://doi.org/10.14529/mmp190206.

7. Bardzinski, P., Walker, P., \& Kawalec, W. (2018). Simulation of random tagged ore flow through the bunker in a belt conveying system. International Journal of Simulation Modelling, (4), 597-608. https:// doi.org/10.2507/IJSIMM17(4)445.

8. Pihnastyi, O., \& Khodusov, V. (2020). Development of the controlling speed algorithm of the conveyor belt based on TOU-tariffs. Proceedings of the $2^{\text {nd }}$ International Workshop on Information-Communication Technologies \& Embedded Systems, ICTES 2020, Mykolaiv, Ukraine, November, (2762) 73-86. Retrieved from http://ceur-ws. org/Vol-2762/paper4.pdf.

9. Kiriia, R., \& Shyrin, L. (2019). Reducing the energy consumption of the conveyor transport system of mining enterprises. International Conference Essays of Mining Science and Practice, (109). https://doi. org/10.1051/e3sconf/201910900036.

10. Marasova, D., Andrejiova, M., \& Grincova, A. (2017). Creation of the project of a logistic system for transportation of minerals - case study. TEM Journal, 6(2), 205-213. https://doi.org/10.18421/ TEM62-03.

11. Pihnastyi, O., \& Khodusov, V. (2018). Model of a composite magistral conveyor line. IEEE International Conference on System analysis 
\& Intelligent computing, (pp. 68-72). Kyiv, Ukraine: Kyiv Polytechnic Institute. https://doi.org/10.1109/saic.2018.8516739.

12. Yang, G. (2014). Dynamics analysis and modeling of rubber belt in large mine belt conveyors. Sensors \& Transducers, 81(10), 210-218.

13. Lu, Yan, Lin, Fu-Yan, \& Wang, Yu-Chao (2015). Investigation on influence of speed on rolling resistance of belt conveyor based on viscoelastic properties. Journal of Theoretical and Applied Mechanics, 45(3), 53-68. https://doi.org/10.1515/jtam-2015-0017.

14. Sakharwade, S., \& Nagpal, S. (2019). Analysis of transient belt stretch for horizontal and inclined belt conveyor system. International Journal of Mathematical, Engineering and Management Sciences, 4(5), 1169-1179. https://doi.org/10.33889/IJMEMS.2019.4.5-092.

15. Kulinowski, P. (2014). Simulation method of designing and selecting tensioning systems for mining belt conveyors. Archives of Mining Sciences, 59(1), 123-138. https://doi.org/10.2478/amsc-2014-0009.

16. Pihnastyi, O., \& Khodusov, V. (2020). Hydrodynamic model of transport system. East European Journal of Physics, (1), 121-136. https://doi.org/10.26565/2312-4334-2020-1-11.

17. Manjgo, M., Piric, E., Vuherer, T., \& Burzic, M. (2018). Determination of mechanical properties of composite materials-the rubber conveyor belt with cartridges made of polyester and polyamide. Annals of the Faculty of Engineering Hunedoara, 16(1), 141-144.

18. Karolewski, B., \& Ligocki. P. (2014). Modelling of long belt conveyors. Maintenance and Reliability, 16(2), 2.

19. Lawson, B. (2017). Overland Conveyor: Control System Re-design and Implementation. PeruMin. 1-10. Retrieved from https://www.semanticscholar.org/paper/Overland-Conveyor-\%3A-Control-System-Re-design-and-Lawson/a4d3dda013402e 1e5b98aa5c4547d886b84a4983.

\section{Аналіз напруження на стрічці конвеєра (модель Maxwell-element)}

\section{О. М. Пігнастий, С. М. Чернявська}

Національний технічний університет «Харківський політехнічний інститут», м. Харків, Україна, е-mail: pihnastyi@gmail.com

Мета. Для конвеєрної стрічки, матеріал якої відповідає Maxwell моделі пружного елемента, виконати аналіз причин виникнення поздовжніх динамічних напружень i дослідити особливості поширення динамічних напружень уздовж маршруту транспортування матеріалу.

Методика. Для розрахунку величини статичних і динамічних напружень, що виникають у конвеєрній стрічці, використано апарат математичної фізики.

Результати. Записане хвильове рівняння, що визначає поширення поздовжніх коливань у конвеєрної стрічки, матеріал якої відповідає моделі Мaxwell-елемента. Отримано вираз для розрахунку швидкості поширення пружних коливань уздовж конвеєрної стрічки, частоти коливань і довжини їх хвилі. Визначено характерний час релаксації збурень. Для рішення хвильового рівняння використано метод послідовного наближення. Дана оцінка характерного часу прискорення конвеєрної стрічки, за якого відсутні руйнування матеріалу конвеєрної стрічки.

Наукова новизна. Полягає в удосконаленні PDE-моделей транспортних систем конвеєрного типу, що використовуються для проектування систем управління швидкістю руху стрічки при обмеженнях на режими управління швидкістю. Показано, що в режимах прискорення або уповільнення конвеєрної стрічки ефекти, пов'язані з виникненням і поширенням динамічних напружень уздовж конвеєрної стрічки, через характеристики матеріалу, що відповідають моделі елемента Maxwell, $€$ незначними.

Практична значимість. Полягає в тому, що отримані результати дозволяють визначити обмеження на режими розгону або гальмування конвеєрної стрічки, які запобігають її виходу з ладу і підвищенню зносу. Це відкриває перспективи для проектування ефективних систем управління параметрами конвеєрної стрічки, нерівномірно завантаженої матеріалом уздовж транспортного маршруту.

Ключові слова: конвеєр, розподілена система, регулювання швидкості стрічки, конвеєр, PDE-модель, Maxwell element, Hookean element

Recommended for publication by H. Ye. Filatova, Doctor of Technical Sciences. The manuscript was submitted 02.02.21. 